indicators of distance; here the methods become less reliable and the uncertainties increase yet further. Supergiant galaxies then act as stepping stones to remoter regions.

It began with the Greeks. RowanRobinson gives them a page or two and then jumps, as one expects in an astronomer's history of astronomy, from Aristotle to Copernicus. The Epicurean system (an infinite atomic universe) and Stoic system (an island cosmos surrounded by an infinite extracosmic void) receive scant attention, although both dominated the intellectual climate of the ancient world. The great historical drama of the mediaeval revival of the Aristotelian system, the eclipse of this system in the late Middle Ages by a renascent Stoic system, the rebirth of the Epicurean system, and the eventual overthrow of the Stoic system in the Great Debate of the 1920 s also receives little recognition. We are told that in the seventeenth century Cassini measured the Sun-Earth distance to within 10 per cent of the modern value, but not that Newton, by using James Gregory's photometric method of comparing the outer planets with the brightest stars, determined with astounding accuracy (within a factor of two for Sirius) the distance of the nearest stars.

In a chapter entitled "The Cosmological Models", which is devoted to theoretical topics, the author discusses dynamic models, redshifts, proper and luminosity distances, the early universe, and the motion of the Solar System relative to the microwave background and to the Local Supercluster. Perhaps more such analysis in the other chapters would have helped the reader to surmount the mountains of data to be found in them.

The axioms or irreducible assumptions of modern cosmology rarely receive adequate attention, and the book would have benefited from some discussion of these hidden assumptions. The Hubble (and deceleration) term tell us how the universe expands. But how exactly do we need to know its value? Theorists first postulated the velocity-distance law, which applies at any instant throughout a homogeneous expanding universe. But when we look out in space we also look back in time, and homogeneity (unlike isotropy) cannot be directly seen. Observations made on the backward light cone are adjusted for evolutionary effects and mapped in a hypothetical homogeneous space. At best we verify that redshifts and estimated distances are consistent within the theoretical frame of a geometric and dynamic model that is itself unverified. Perhaps our models are too simple and we do not know enough cosmology to make an exact value of the Hubble term meaningful?

Edward Harrison is Professor of Astronomy in the Department of Physics and Astronomy. University of Massachusetts, Amherst. Massachusetts 01003, USA.

\title{
Halley's comet in print
}

\section{David W Hughes}

ON 16 October 1982 Halley's comet was picked up using a charge-coupled device at the prime focus of the $5.1 \mathrm{~m}$ Hale telescope on Mount Palomar. It has been monitored ever since. As it approaches the Sun it brightens and will become just visible to the naked eye between December 1985 and April 1986. But there are two problems for observers. On 9 February 1986 the comet is at its closest to the Sun and for a six-week period around then is in too bright a region of sky to be easily visible. Also, between December and April it sweeps from the northern to the southern sky, requiring the northern observer to reciprocate by moving to the southern hemisphere. Unfortunately planet Earth does not get very close to the comet this time, so we are not going to be overawed by startling searchlight-like beams radiating up from the twilight horizon. In fact the mere act of catching sight of the comet will require some effort.

Halley's return to the inner Solar System has been greeted by a whirlwind of books, and thus a rather rare state of affairs as far as the reviewer is concerned. Most of them in fact say much the same things, use the same illustrations and are aimed at a like audience. Most are written by non-specialists who, for simplicity, have consulted only secondary sources of information and have consequently made many mistakes. Reviewing them is akin to essay-marking. To help the prospective buyer the books are divided into categories, with a star rating for each according to whether it is thought to be excellent, good, indifferent or poor. The five-star rating is reserved for those rare books in the pile that will "last", to be consulted around AD 2061 when Halley's comet returns once more.

The categories are as follows: (i) Books specifically designed to help the reader see the comet (the message being that you have a-once-in-a-lifetime chance so make the most of it); (ii) guides for teachers, that is books specifically designed for the organizers of classes; (iii) specialist books; and (iv) general books.

Halley's Comet by Francis Reddy leads the first category. It abounds with good advice: "If you want to see the comet you had better prepare for it, familiarize yourself with the constellations through which Halley moves, get away from cities, use your binoculars and travel south". Twenty maps are provided, for three Earth latitudes $\left(55^{\circ} \mathrm{N}, 40^{\circ} \mathrm{N}\right.$ and $\left.35^{\circ} \mathrm{S}\right)$. These not only show the comet and its tail against the starry background but also include (where appropriate) the Moon, Mars and Jupiter. A superb three-dimensional model of the orbits of the comet and Earth is an additional bonus.

Such models are a great help when it comes to visualizing the movement of the comet with respect to the Sun and Earth. and Perihelion Scientific have produced one, Halley's Comet Survival Kit, which is $85 \mathrm{~cm}$ across. Another accompanying model enables you to calculate the altitude and azimuth of the comet throughout the November 1985-May 1986 period. Both are great fun to assemble and use.

If you are happier with a planisphere, David Chandler has designed a set of three (for northern latitudes $26^{\circ}, 35^{\circ}$ and $44^{\circ}$ ). These show the comet's path through the constellations and it is simplicity itself to calculate when and where it can be seen. Unfortunately there are no hints as to its brightness.

Halley's Comet Finder by Ben Mayer is aimed more at the astronomically initiated and gives a detailed review of the comet's journey across the sky. The section on astrophotography in this book is most useful.

For the complete beginner the editors of Sky and Telescope have produced $\mathrm{Mr}$. Halley's Comet (I've no idea why they refer to a man who was an eminent professor and had two doctorates as "Mr."). This is an excellent and inexpensive guide mar. red only by the sparsity of stars on the sky map. The fact that a pair of binoculars has only a limited field of view is rightly stressed, but the difficulty of finding the comet and recognizing stars in the field is somewhat overlooked. The guide seems to be designed in the hope that the comet would be much brighter.

Moving into the classroom, both Comet Halley Returns and Halley's Comet Activities Manual get good marks and will provide science teachers and their scholars with hours of activity understanding comets, modelling their orbits, recording observations, computing examples of Keplerian motion, introducing the life and times of Edmond Halley and trying to appreciate his achievement. Halley's Comet: Teacher's Notes comes with posters and is biased towards young $(9-14)$ or innumerate pupils (and supposedly innumerate teachers too!). It approaches cometary science from a sociological and refreshingly critical standpoint - I'm still considering "the possibility that women astronomers do not appear in astronomy books because those books are generally written by men", one of the topics suggested for classroom discussion. Mary Ashby, the author, has a clear grasp of what children find interesting and what they find difficult to understand, and has planned a series of exercises for explaining difficult concepts.

Nine books fall into the specialist category, two of which are bibliographies. Ruth S. Freitag lists 3,289 references to both popular and scientific cometary literature. The list is alphabetical by author and each 
reference is followed by a short description of the item. This book is an indispensable source for anyone seeking data on the comet's previous apparitions. technical literature on the Halley spacecraft missions or manifestations of popular interest in comets. Just turn to the index, and look up, for example. "Essays and sketches, humorous"; "fiction"; "recovery (1759)"; "transits across the sun's disk"; "music"; and "mass spectroscopy". What a godsend this book is. I hope that Ruth Freitag can be persuaded to bring the work up to date in, say, 1990 when the present hullabaloo has died down.

Bruce Morton's bibliography will be less useful because he has deliberately omitted all non-English language source material. The listing is chronological but is backed up with an author and subject index. Morton only lists 1,301 items but does include many not covered by Freitag. Researchers will need both books.

Fire and Ice by Roberta J.M. Olson is an art historian's view of comets and has been published to accompany an exhibition of comets in art at the National Air and Space Museum in Washington, DC. The main attraction of Olson's book is the art reproductions. There are over a hundred pictures of comets, many in colour. Rackham, Moreau, Turner, Gérard, Blake, Daumier, van Stolk, Stech, Scott, Giotto - the list of artists is impressive. The text serves two purposes, first, to introduce the pictures and fit them into the context of the history of art, and secondly to weave in the development of man's fear and understanding of comets as shown in the paintings, engravings and illustrations of the day. All this is both entertaining and enlightening, but let me mention two minor quibbles. If someone has gone to the trouble to paint "Dr Halley" across the top of the Phillips portrait of our hero, why entitle it "Sir Edmund Halley" in the book? He wasn't knighted and he spelt his christian name Edmond. Also it must be remembered that Halley's comet was not that famous before 1705 . Giotto might not have had to remember the comet of 1301 ; he might have popped out in December 1304 and painted the long-period comet that was in the sky then.

Peter Lancaster-Brown in Halley and his Comet has concentrated on the nonartistic historical aspects of the story, and creatively charts the transition of comets from astrological portents (in preHalleyan times) to their present status as unusual astronomical objects. The author has produced a most readable book, but one in which he has not resisted the temptatation to fill in some of the gaps: lines such as "We might surmise without stretching credulity ..." often end in rather too imaginative conjecture. If Newton was a latent homosexual, and Halley a philanderer, I would like chapter and verse.

All serious cometary historians should get a copy of La Comète de Halley: Hier,
Aujourd hui, Demain by J. Alexandre and S. Debarbat. This is a small folder containing a collection of reproductions of Halley comet documents from the Paris Observatory. The Lubientietz maps and the drawings by Hevelius, Arnold, La Hire, J.-D. Cassini and Schwabe are fascinating, while Messier's hand-written account of the 1758 apparition is in the first division of historic documents.

Comet Fever by Donald Gropman has as its main theme the 1910 appearance of the comet and especially the dramatic events of the night of 18-19 May when the Earth swept through the comet's tail. We are told of sealed windows, absenteeism from home and work, mass prayer ses-

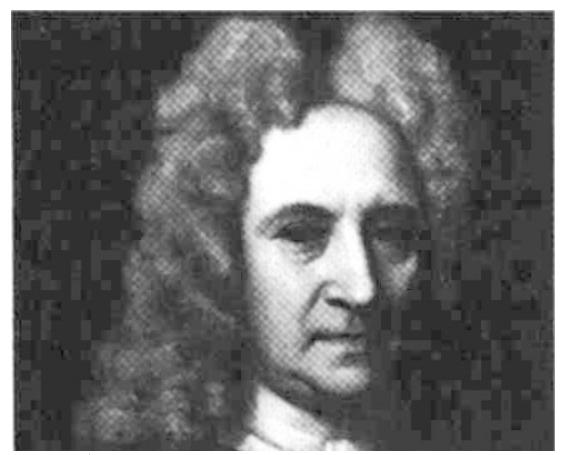

Richard Phillip's portrait of Halley circa 1721.

sions and, to cap it all, all the news fit to print about the infamous Oklahoma 19 - year - old - naked - virgin - sacrifice drama. Other chapters skim over past apparitions of Halley and aspects of modern cometary science, making in all a wellwritten, extremely readable book.

Fred L. Whipple is the doyen of comet scientists having worked extremely profitably in the field of cometary astronomy for 50 years. What he has to say about comets is certainly worth reading and his book, The Mystery of Comets, is superb. Too few scientists take the time to explain the complexities of their subject to a general audience. Whipple has left nothing out - if you want a synopsis of what is known about comets and, even more exciting, what is still beyond our present grasp, this is the book for you.

Another book that will be consulted for decades is Halley's Comet in History, edited by F.R. Stephenson and C.B.F. Walker, which emphasizes the Babylonian and Chinese records of the comet between $240 \mathrm{BC}$ and $\mathrm{AD} 1531$. The 13page, line-by-line translation of a $164 \mathrm{BC}$ Babylonian cuneiform tablet is rather strong meat for the casual browser, but if you need the historical information this is where to look. I wish more than one figure showing the comet's path across the sky had been included - the book would have been greatly enhanced by including a set of these for the relevant 23 apparitions

Comet by Carl Sagan and Ann Druyan is a visual and intellectual feast, combining a host of specially commissioned colour illustrations with a text that, for the breadth of insight into the past, present and future of cometary science, is way ahead of the rest of the field.

Standing back from all the razzamatazz surrounding this apparition, the book concentrates on the fundamentals: why have comets worried people, what have scientists and philosophers made of them, what is their origin, composition and fate? The Sagans inquisitive enthusiasm is infectious. Sometimes they approach that danger zone where the gap between fact and speculation is overlooked, but they are soon forgiven. For me, comets will never be the same again. Cometary science can only blossom with such champions.

Finally, to the general books - those containing a bit of everything, history, comet lore and an observer's guide. Confronted with eight of them the reviewer is forced to list them in order of preference, a difficult task because they all have "curate's egg" properties. First past the post is Patrick Moore and John Mason's The Return of Halley's Comet. The maps are excellent, giving you a real chance of spotting the comet, and the review of comet science and decay is impressive. Make sure you get the new edition.

Close behind are Brian Harpur's The Official Halley's Comet Book and Mark Littmann and Donald K. Yeomans's Comet Halley: Once in a Lifetime. Both are superbly illustrated and overflowing with anecdotes. Harpur's review of cometary poetry and literature is masterly, while Littmann and Yeomans put across the scientific message superbly. With both, however, you will need additional help to find the comet.

In much the same category we find $A$ Comet Called Halley by Ian Ridpath and Terence Murtagh. The text is excellent but some of the illustrations are a touch odd; surely the Vega spacecraft doesn't look like that! And it would be much easier to find the comet if it was shown with respect to compass points and elevation, and not just vaguely trundling across the constellations.

Occupying the uninspiring section where the errors proliferate and the illustrations become even more blurred we find four books by Richard Flaste et al., John Tullius, Donald Tattersfield and Isaac Asimov. Reading these convinces me that there are many better ways of spending one's time and money.

The entire collection (which, incidentally, is by no means a comprehensive display of Halleyiana) is listed in the table on the following page. But, to summarize: if you want to see Halley's comet read Francis Reddy; if you want to stay in your armchair with your feet up, read Brian Harpur, and Sagan and Druyan; if you want to know about comets in general you can do no better than Fred Whipple; and if you want to find something out for yourself get Ruth Freitag's bibliography.

David W. Hughes is Senior Lecturer in Astronomy and Physics, Department of Physics, University of Sheffield, Sheffield S3 $7 R H$. 
Halley's comet in print — details of the publications

Author/editor

Publisher

Pp.

Price

Rating

Title
Seeing the comet
Halley's Comet
Halley's Comet Survival Kit
The Night Sky Planisphere with
Halley's Path
Halley's Comet Finder
Mr. Halley's Comet: Everyone's
Complete Guide to Seeing the
Celestial Event

Francis Reddy

Halley's Comet, 1755-1984:

A Bibliography

Fire and Ice: A History of Comets in Art

Halley and his Comet

La Comète de Halley: Hier, Aujourd'hui, Demain

Comet Fever: A Popular History of Halley's Comet

The Mystery of Comets

Halley's Comet in History

Comet

\section{General books}

The Return of Halley's Comet (new edition)

The Official Halley's Comet Book

Comet Halley: Once in a Lifetime

\section{A Comet Called Halley}

The New York Times Guide to the Return of Halley's Comet

The Science Digest Book of Halley's Comet

Halley's Comet

Asimov's Guide to Halley's Comet: The Awesome Story of Comets
Tom Gaffney et al.

David Chandler

Ben Mayer

Editors of Sky and

Telescope

R.O.Chapman and

R. Lynn Bondurant, Jr

George S. Mumford

Mary Ashby

Ruth S. Freitag

Bruce Morton

AstroMedia, Milwaukee, $\quad 59$

Perihelion Scientific,

NASA, EP 197

Roberta J.M. Olson

Peter Lancaster-Brown

J. Alexandre and

S. Debarbat

Donald Gropman

Fred L. Whipple

F.R. Stephenson and

C.B.F. Walker

Carl Sagan and

Ann Druyan

Patrick Moore and John Mason

Brian Harpur

Mark Littman and Donald K. Yeomans

Ian Ridpath and Terence Murtagh Richard Flaste et al.

John Tullius

Donald Tattersfield

Isaac Asimov WI/Pan, London Paoli, PA

Sky Publishing, Cambridge, MA Perigee, New York Sky Publishing

Sky Publishing

Inner London Education

Authority

Library of Congress,

Washington, DC

Greenwood Press,

Westport, CT/

Eurospan, London

Walker, New York

Blandford, Poole, Dorset/Sterling, New York

Observatoire de Paris

Fireside (Simon \&

Schuster)

Smithsonian Institution

Press/Cambridge

University Press

British Museum

Publications, London

Random House/

Michael Joseph

Patrick Stephens,

Wellingborough,

Northants, UK/Warner,

New York

Hodder \& Stoughton,

London/David \& Charles, North Pomfret, VT

American Chemical

Society, Washington DC

41

Pbk $\$ 2$

$\$ 4$

$£ 5.50$

f7.95
.

North America

$\$ 14.95$;

elsewhere

$\$ 20.25$

$\$ 5.95$

Pbk $\$ 5.95$

$\$ 2$

41

53

$£ .50$

555

$\$ 26$

$\$ 35$,

$£ 43.50$

144

Hbk $\$ 24.95$; pbk $\$ 14.95$

186

$£ 9.95$,

$\$ 12.95$

FF 22

189

Pbk $\$ 7.95$

276

Hbk \$24.95,

£12.95;

pbk $\$ 12.50$

64

Pbk $£ 5.50$

240

$\$ 24.95$, $£ 12.95$

128

Pbk $£ 4.99$, $\$ 6.95$

184

£8.95. $\$ 15.95$

Cambridge University

Press

Times Books,

New York

136

North America

hbk \$19.95.

pbk \$12.95;

elsewhere

hbk $\$ 23.95$,

pbk $\$ 15.95$

Pbk $£ 2.95$,

$\$ 4.95$

Avon, New York

Hbk \$16.95;

pbk $\$ 7.95$

Basil Blackwell

$\$ 9.95$

Walker, New York 